\title{
Absence of Ventilatory Responses to Alternating Breaths of Mild Hypoxia and Air in Infants Who Have Had Bronchopulmonary Dysplasia: Implications for the Risk of Sudden Infant Death
}

\author{
NICOLE A. CALDER, BRIDGET A. WILLIAMS, JOHN SMYTH, ANDREW W. BOON, \\ PREM KUMAR, AND MARK A. HANSON
}

\begin{abstract}
The Fetal and Neonatal Research Group, Department of Obstetrics and Gynaecology, University College School of Medicine, University College London, London WCIE 6HX [N.A.C., B.A.W., M.A.H.]; the Department of Paediatrics, Roval Berkshire Hospital, Reading RGI 5AN [J.S., A.W.B.]; and the Department of Physiology. University of Birmingham, Birmingham B15 2TJ [P.K.], United Kingdom
\end{abstract}

\begin{abstract}
Infants who have had bronchopulmonary dysplasia (BPD) are at an increased risk of sudden infant death syndrome. Because failure of the cardiorespiratory response to hypoxia is suggested to play a key role in sudden infant death syndrome, we tested the hypothesis that infants who have had BPD have a reduced respiratory chemoreflex response to hypoxia. We examined the reflex respiratory responses to breath-by-breath alternations in fractional inspired oxygen concentration in eight infants who had had BPD (mean gestation $=27 \mathrm{wk}$, mean postnatal age $=93 \mathrm{~d}$ ) who were no longer on supplemental oxygen and compared the responses with those of 12 preterm infants who had not required supplemental oxygen or been mechanically ventilated since birth (mean gestation $=30 \mathrm{wk}$, mean postnatal age $=38 \mathrm{~d}$ ). For test runs we alternated fractional inspired oxygen concentration through two gas delivery lines between 0.21 and 0.16 on a breath-by-breath basis, and for control runs we alternated the inspirate between the two gas lines with a fractional inspired oxygen concentration of 0.21 in each. Respiration was measured using inductance plethysmography. infants with BPD showed no significant differences between test and control responses for any respiratory variable. In contrast, all respiratory variables in the preterm infants showed test responses significantly greater than control. We speculate that the "blunted" chemoreflex respiratory response seen in infants with BPD may predispose them to subsequent respiratory failure, but we do not know which component of the chemoreflex is impaired. (Pediatr Res 35: 677-681, 1994)
\end{abstract}

\section{Abbreviations}

BPD, bronchopulmonary dysplasia $\mathrm{FIO}_{2}$, fractional inspired oxygen concentration SIDS, sudden infant death syndrome $\mathbf{P a O}_{2}$, arterial oxygen partial pressure $\mathrm{PaCO}_{2}$, arterial carbon dioxide partial pressure $V_{T}$, tidal volume

Received March 23, 1993; accepted December 30, 1993

Correspondence: Nicole Calder, Department of Obstetrics and Gynaecology, University College School of Medicine, University College London, 86-96 Chenies Mews. London WC1E 6HX, UK.

Supported by the Foundation for the Study of Infant Deaths. Wellcome Trust. and Medical Reasearch Council.
$T_{1}$, inspiratory time

$T_{E}$, expiratory time

Infants discharged from neonatal intensive care units have an increased risk of postneonatal mortality. BPD is an additional complication in those infants who have been diagnosed with respiratory distress syndrome, and infants who have had BPD are a group in which the incidence of SIDS is reported to be as much as 7 times higher than the population as a whole (1). The reason for this increased risk of SIDS is not known.

Infants with BPD are burdened with decreased dynamic compliance, increased airway resistance, increased functional residual capacity, and airway hyperreactivity for some time after their discharge from intensive care $(2,3)$. Although considerable, these factors alone may not be sufficient to prevent a ventilatory response to changes in blood gases occurring during respiratory failure, and so it seems possible that infants with BPD may also suffer from a reduced gain of their respiratory chemoreflexes.

It was our hypothesis that infants with BPD are unable to respond to hypoxic conditions because of impaired chemoreflex control. A failure in chemoreflex respiratory control and the response to hypoxia has been suggested for many years to play a role in SIDS (4). We felt that a weak response of the infant with BPD to a mild hypoxic challenge possibly could explain the link between infants with BPD and the high incidence of SIDS.

Infants dying of SIDS must fail to mount an appropriate arousal response to acute hypoxia and hypercapnia experienced before death, regardless of the precipitating factors causing cardiorespiratory deterioration. In newborn lambs, cutting the carotid sinus nerves markedly reduces the arousal response to hypercapnia and hypoxia $(5,6)$, confirming the role of the carotid chemoreceptors or carotid baroreceptors in initiating the response. Arousal responses in newborn infants occur with low concentrations of steady state fractional inspired carbon dioxide (7), i.e. 0.04 , although term and preterm infants tolerate concentrations of $0.05-0.07$ fractional inspired carbon dioxide during normoxic rebreathing (8). An $\mathrm{FlO}_{2}$ of 0.15 elicited arousal responses in 14 of 22 normal infants compared with only one of 11 who had experienced an apparent life-threatening event (9), and more pronounced hypoxia $\left(\mathrm{FlO}_{2} 0.11\right)$ caused nine of nine control infants to arouse in contrast to only 19 of 50 infants who experienced an apparent life-threatening event (10). Arousal responses to an $\mathrm{FlO}_{2}$ of 0.11 were recorded in 11 of 12 infants with BPD (11); however, they experienced prolonged apnea and 
bradycardia after arousal, with four requiring assisted ventilation to restore spontaneous breathing.

With increasing $\mathrm{PaCO}_{2}$ and declining $\mathrm{PaO}_{2}$ levels occurring terminally in the infant who dies of SIDS, the question remains as to why no appropriate arousal response occurs. The failure to respond may lie at the level of the arterial chemoreceptor if previous hypoxia and low oxygen saturation have disrupted normal chemoreceptor function, e.g. by reducing or delaying the resetting of chemosensitivity that normally occurs postnatally $(12-16)$. It is also possible that the defect lies in the CNS and that an increased chemoreceptor afferent input fails to elicit an adequate increase in respiratory output or to produce arousal.

We have developed a noninvasive test of chemoreflex sensitivity, the alternate breath test, that delivers a rapidly alternating stimulus to the peripheral chemoreceptors in the arterial blood and have used it to measure peripheral chemoreflex sensitivity in healthy term infants, kittens, and lambs. The respiratory response to the alternate breath test is mediated predominantly by the carotid chemoreceptors (13). It is capable of detecting the naturally occurring increase in carotid chemoreceptor sensitivity to hypoxia with increasing postnatal age in kittens (12) and babies (14). In this study, we used the alternate breath test to measure the sensitivity of respiratory chemoreflexes in BPD and preterm control infants.

\section{SUBJECTS AND METHODS}

Infants were recruited from the neonatal units at University College Hospital, London, and The Royal Berkshire Hospital, Reading. Local ethical committee approval and written parental consent were obtained. Infants were well at the time of the study, were not receiving supplemental oxygen, had oxygen saturations greater than $90 \%$ when breathing air, and were due to be discharged from the unit within $1 \mathrm{wk}$.

Infants with BPD were defined as preterm (gestation $<36 \mathrm{wk}$ ), having been mechanically ventilated for at least $7 \mathrm{~d}$, and requiring a minimum of $28 \mathrm{~d}$ in supplemental oxygen for the treatment of BPD. They had radiographic findings consistent with chronic lung disease. Control infants were preterm but had not required mechanical ventilation or supplemental oxygen after birth.

The infants were studied during quiet sleep as judged behaviorally (17) and $1-2 \mathrm{~h}$ after a feeding. Tests were performed in the neonatal unit at an ambient temperature of $23-25^{\circ} \mathrm{C}$. Most infants were wearing a one-piece toweling outfit at the time of study and were covered with a single blanket.

The method used has been previously described by Williams et al. (14). The experimental setup is shown in Figure 1. Infants were studied in the lateral or supine position. Breathing was measured by inductance plethysmography (Respitrace Corp., Ardsley, NY) calibrated by the least squares graphical technique described by Sackner et al. (18) to derive scaling factors for the rib cage and abdominal signals. The Respitrace plethysmograph was adjusted accordingly. The $\mathrm{V}_{\mathrm{T}}$ signal derived by summation of the rib cage and abdominal signals was passed on-line from the Respitrace to a BBC Master 128 Acorn microcomputer (British Broadcasting Corp., Cambridge, UK) and digitized at $100 \mathrm{~Hz}$ for off-line analysis. Inspired gas was humidified and supplied to the infant at a rate in excess of minute ventilation, i.e. at $2.0-2.5 \mathrm{~L} / \mathrm{min}$, via a nasal catheter (no. 1615, Salter Labs, Arvin, $\mathrm{CA}$ ) attached via a Y-connector to two gas delivery lines. The flow of gas in each delivery line was set using rotameters connected to cylinders of medical grade air $\left(\mathrm{FIO}_{2} 0_{0.21}\right)$ and gas with an $\mathrm{FIO}_{2}$ of 0.16 , with the balance being nitrogen (precalibrated; British Oxygen Co. special gases). Delivery of inspired gas through a pair of three-way solenoid-operated valves was controlled by the computer, which sent a $5-\mathrm{V}$ signal to the solenoid control box at the start of each expiration and switched the gas between an open port to the infant and a diverted port to the atmosphere. During test runs, breath-by-breath alternations of air and an $\mathrm{FIO}_{2}$ of 0.16 were delivered for up to 100 breaths. The endpoint occurred prematurely to this if the infant sighed or if a regular breathing pattern was disrupted by the infant's movements. During control runs, air was delivered in both gas lines. A minimum of two test and two control runs was necessary for the data to be included in the analysis. Oxygen saturation was measured throughout the procedure by a pulse oximeter operating in the beat-to-beat mode (Nellcor N200, Nellcor Inc., Hayward, CA) and never fell below 90\%. The saturation monitor was used as safety device and a measure of patient well-being, inasmuch as it was not capable of responding to the very small changes in oxygen saturation produced by breath-by-breath changes in $\mathrm{FiO}_{2}$.

The method of data analysis has been previously described by Williams et al. (14). For each breath, the $V_{T}, T_{1}(s)$, and $T_{E}(s)$ were found and from these were calculated respiratory frequency (f) $\left[f=60 /\left(T_{1}+T_{E}\right)\right.$ in breaths $/$ min $]$, mean inspiratory flow $\left(V_{T} /\right.$ $\left.T_{1}\right)$, respiratory timing $\left[T_{1} /\left(T_{1}+T_{E}\right)\right]$, and ventilation $\left(V_{T} \cdot f\right)$. For each respiratory variable, the difference between a pair of consecutive breaths was expressed as a percentage of the average of the two breaths. Each breath was compared with the immediately preceding breath, and the percentage alternation was plotted cumulatively with respect to breath number, reversing the sign $(+$ or -$)$ for every second pair of breaths. Thus, a regular alternation produced a consistent deviation from the baseline. A slope was fitted to the line by regression analysis, and its magnitude indicated the mean breath-by-breath percentage alternation. The magnitudes of the slopes for test and control runs were compared by using the Mann-Whitney $U$ test within each of the study groups. Baseline measurements of frequency, $T_{l}, T_{E}$, and timing were compared between preterm control and infants with BPD using the Mann-Whitney U test. Values were considered significant when $p$ was $<0.05$.

\section{RESULTS}

Patient data are given in Table 1. BPD infant 3 was the same as BPD infant 1 but was studied when older. The exclusion of this repeat study at a greater postnatal age would not change the statistical significance of the results, so it was included in the analysis. The gestational and postnatal ages and the birth weights of the infants with BPD were significantly different from preterm controls using the Mann-Whitney $U$ test.

Baseline measurements of frequency, $T_{1}, T_{E}$, and timing are given as means in Table 2 . There was no statistically significant difference in baseline values between the preterm control and BPD groups for the four variables using the Mann-Whitney $U$ test.

Figure 2 is an example of the cumulative alternate breath plot and illustrates responses of a preterm control infant $(t o p)$ and an infant recovered from BPD (bottom). The control responses for each of the infants are similar. However, the alternations exhibited for $T_{E}$, frequency, $V_{T}$, and ventilation in the test response of the preterm control infant are not seen in the test response of the infant with BPD.

Figure 3 illustrates the mean control and test responses for each of the seven respiratory variables measured in 12 control infants (from 31 runs) and eight infants with BPD, one of whom was studied at two different postnatal ages (from 21 runs). Infants with BPD showed no significant difference between test and control runs for any of the respiratory variables. In contrast, preterm control infants showed test responses that were significantly different from control responses for $V_{T}, T_{1}, T_{E}$, and ventilation.

\section{DISCUSSION}

Our results demonstrate a markedly reduced response of infants with BPD to the alternate breath test compared with preterm infants who have not had BPD, even though the infants with BPD were no longer oxygen dependent at the time of the study and were well oxygenated in air.

The infants with BPD were significantly younger by gestational age and significantly older postnatally than the preterm infants. 


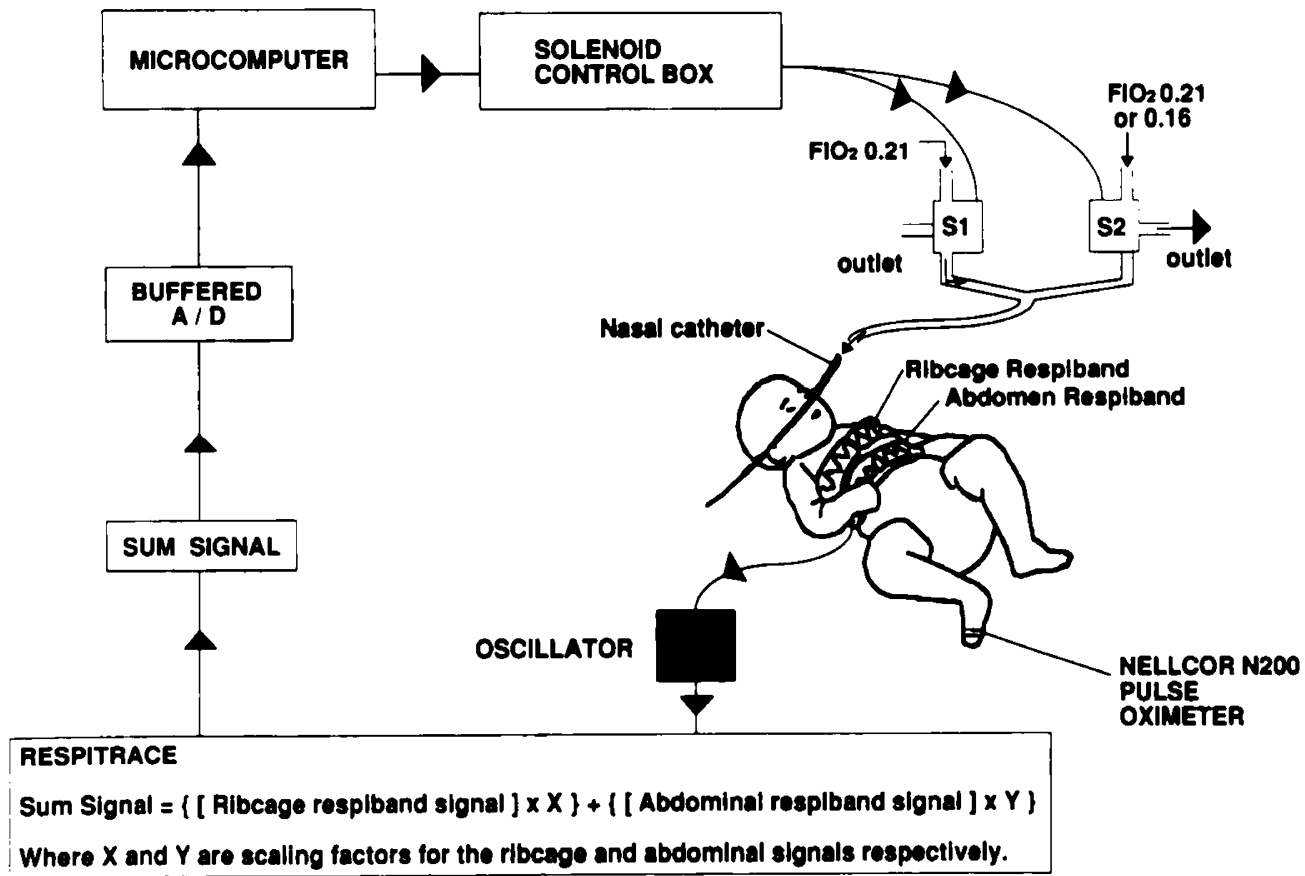

Fig. 1. The experimental setup used for controlling the supply of inspired gas and for measuring and recording the response to alternate breaths of air and test gas $\left(\mathrm{FlO}_{2}\right.$ of 0.16$)$. Gas with an $\mathrm{FlO}_{2}$ of 0.21 is always delivered through solenoid $1(\mathrm{~S} I)$, and a gas with an $\mathrm{FlO}_{2}$ of either 0.21 or 0.16 is delivered through solenoid $2(S 2)$.

Table 1. Patient information

\begin{tabular}{|c|c|c|c|c|c|c|}
\hline \multirow[b]{2}{*}{ Patient no. } & \multicolumn{3}{|c|}{ Control } & \multicolumn{3}{|c|}{ BPD } \\
\hline & $\begin{array}{c}\text { Gestation } \\
\text { (wk) }\end{array}$ & $\begin{array}{l}\text { Birth weight } \\
\text { (g) }\end{array}$ & $\begin{array}{l}\text { Postnatal } \\
\text { age (d) }\end{array}$ & $\begin{array}{l}\text { Gestation } \\
(w k)\end{array}$ & $\begin{array}{c}\text { Birth weight } \\
\text { (g) }\end{array}$ & $\begin{array}{l}\text { Postnatal } \\
\text { age (d) }\end{array}$ \\
\hline 1 & 34 & 1930 & 13 & 29 & 1310 & 49 \\
\hline 2 & 30 & 1730 & 28 & 25 & 825 & 121 \\
\hline 3 & 36 & 2550 & 13 & 29 & 1310 & 62 \\
\hline 4 & 28 & 1700 & 44 & 25 & 760 & 112 \\
\hline 5 & 28 & 1240 & 48 & 25 & 960 & 98 \\
\hline 6 & 31 & 1630 & 19 & 32 & 1560 & 42 \\
\hline 7 & 31 & 1540 & 19 & 28 & 1158 & 85 \\
\hline 8 & 28 & 1070 & 42 & 24 & 555 & 183 \\
\hline 9 & 28 & 1150 & 90 & 27 & 957 & 84 \\
\hline 10 & 29 & 1540 & 42 & & & \\
\hline 11 & 29 & 1486 & 63 & & & \\
\hline 12 & 31 & 1347 & 35 & & & \\
\hline Mean \pm SEM & $30 \pm 0.7$ & $1576 \pm 114$ & $38 \pm 6$ & $27 \pm 0.9$ & $1044 \pm 106$ & $93 \pm 14$ \\
\hline
\end{tabular}

Table 2. Baseline values for respiratory variables (mean $\pm S E M)$

\begin{tabular}{lcccc}
\hline & $\begin{array}{c}\text { Frequency } \\
\text { (breaths/ } \\
\text { min) }\end{array}$ & $\begin{array}{c}\text { Timing } \\
\left(\mathrm{T}_{1} / \mathrm{Ttot}\right)^{*}\end{array}$ & $\mathrm{~T}_{1}(\mathrm{~s})$ & $\mathrm{T}_{\mathrm{E}}(\mathrm{s})$ \\
\hline Control & $55.8 \pm 3.4$ & $0.38 \pm 0.01$ & $0.42 \pm 0.02$ & $0.83 \pm 0.10$ \\
BPD & $61.3 \pm 3.1$ & $0.40 \pm 0.02$ & $0.40 \pm 0.02$ & $0.64 \pm 0.06$ \\
\hline
\end{tabular}

*Ttot, total time.

However, in animals and normal infants, greater postnatal age confers an increased chemoreflex $(11,13,19)$, so on the basis of age alone the infants with BPD should have exhibited a strong chemoreflex. We found in full-term infants studied in the first few postnatal days (approximately $48 \mathrm{~h}$ after birth) and again at 6 wk that no further maturation of the chemoreflex respiratory response to hypoxia occurred during this time (20). Thus, resetting of chemoreceptor hypoxic setting occurs rapidly. Despite the fact that infants with BPD were older postnatally, the difference in the chemoreflex respiratory responses from healthy pre- term babies cannot be explained by the difference in postnatal ages.

We used a hypoxic stimulus in preference to a hyperoxic stimulus to challenge oxygen chemosensitivity for two reasons. First, a hypoxic stimulus moves up the steeper portion of the arterial chemoreceptor response curve, whereas hyperoxia moves along the flatter portion of the hyperbola. Absent or weak responses to hyperoxia could be equally due to the natural shape of the response curve as to some pathologic process, thus diminishing the value of the results. Second, it is against hypoxia that the infant may have to defend itself, so this is the response that we wanted to assess.

The poor response illustrated by the infants with BPD may indicate impairment at several levels, namely in the transmission of the stimulus from the inspired gas to arterial blood, in peripheral chemosensitivity, in central respiratory control, or in pulmonary mechanics. These will be discussed in turn below.

Histologic examination of the lungs of infants with BPD at autopsy indicates somatic growth retardation, reduced lung volume and abnormal lobar volume proportions, decreased alveolar 

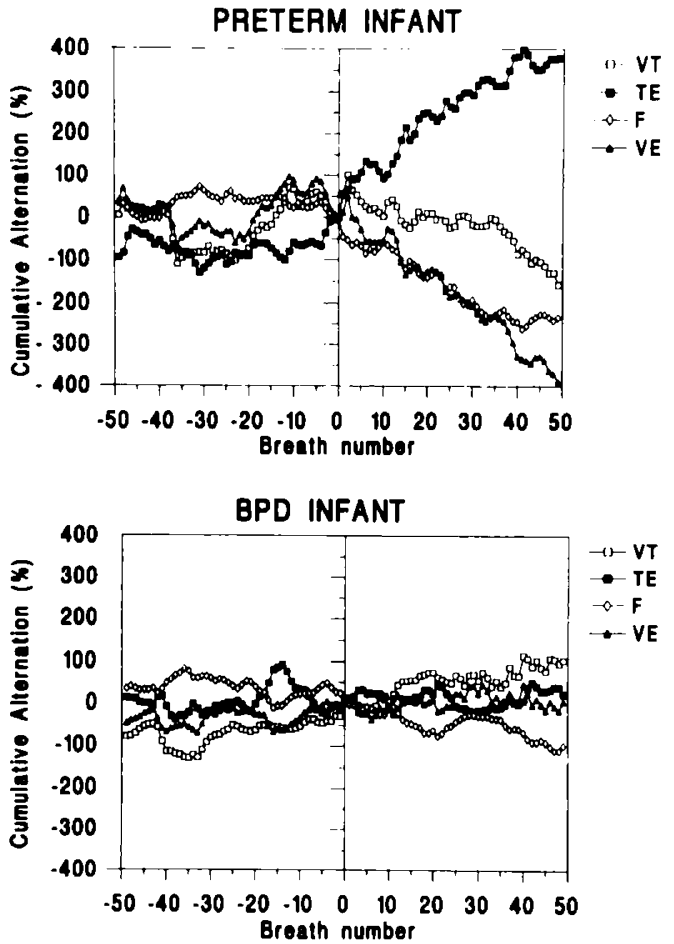

Fig. 2. An example of the cumulative alternate breath plot for a preterm control infant (top) and an infant who had recovered from BPD (bottom). Control responses are plotted to the left and test responses to the right for 50 breaths each. Filled squares represent $\mathrm{T}_{\mathrm{E}}$, open squares represent $\mathrm{V}_{\mathrm{T}}$, open diamonds represent frequency, and filled triangles represent instantaneous ventilation. A slope was fitted to each of the cumulative responses by regression analysis to derive the mean breathby-breath percentage alternation.

number and alveolar hypoplasia, reduced internal surface area, and bronchial and bronchiolar smooth muscle hypertrophy (21). Increased wall thickness, increased muscularization of peripheral arteries, and reduced cross-sectional perfusion area occurred in infants with BPD who had survived past 1 mo of age (22). These factors may reduce the amplitude of the oscillations in $\mathrm{PaO}_{2}$ that occur when $\mathrm{FlO}_{2}$ is made to alternate $(23,24)$. The smaller oscillations in $\mathrm{PaO}_{2}$ would correspondingly lead to smaller oscillations in chemoreceptor discharge, and hence the alternation in respiratory variables produced will be exrected to be less. This seems unlikely because the infants were no longer oxygen dependent. However, inasmuch as the infants were all due for discharge, none had indwelling arterial lines, so it was not possible to obtain baseline values for $\mathrm{PaO}_{2}$ or $\mathrm{PaCO}_{2}$. In the absence of an indwelling rapidly responding $\mathrm{PaO}_{2}$ electrode, it was not possible to evaluate the extent to which a reduction in the stimulus accounted for our results. It was not possible to use a transcutaneous $\mathrm{PO}_{2}$ electrode to quantify the stimulus either, because the intrinsic stabilizing time of the electrode prevents it from responding to a rapidly alternating $\mathrm{PaO}_{2}$. Similarly, the small fluctuations in oxygen saturation produced by the test were not detected above random fluctuations by our monitor operating in the beat-to-beat mode. It will be important in future studies to determine baseline oxygenation using, for example, transcutaneous $\mathrm{PO}_{2}$ measurement. Baseline $\mathrm{PO}_{2}$ may be important in determining the development of several aspects of respiratory control.

Previous use of the alternate breath test in newborn infants has shown the respiratory response to alternations in $\mathrm{FiO}_{2}$ to increase in the first week of life, both in terms of the number of variables showing a response and in the magnitude of the response (14). This time course follows the maturation of respiratory chemoreflexes measured in the kitten and lamb $(12,13,19)$. Carotid sinus denervation in newborn lambs abolishes the ventilatory response to alternations in $\mathrm{FIO}_{2}$ and confirms that the carotid chemoreceptors elicit the response (13). Chronically hypoxic kittens exhibit delayed resetting of chemoreceptor hypoxia sensitivity and a blunted chemoreflex response (12). Thus, the blunted response seen in infants with BPD may be caused by chronic hypoxia, inasmuch as infants with BPD are said to be borderline hypoxemic (25). In the absence of the increase in $\mathrm{PaO}_{2}$ that normally occurs after birth, the time for peripheral chemoreceptor resetting and hence for maturation of respiratory chemoreflexes may be considerably delayed in newborn infants.

Infants recovering from respiratory distress syndrome have lower dynamic compliance than normal preterm infants (3) and increased baseline airway resistance compared with expected control values (2). Thus, a given stimulus may be equally rec-
CONTROL

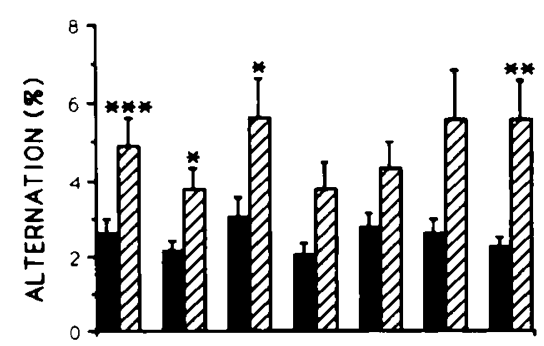

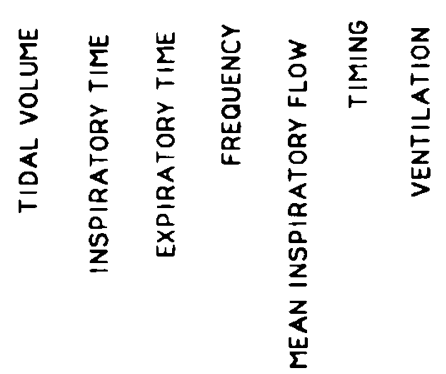

BPD

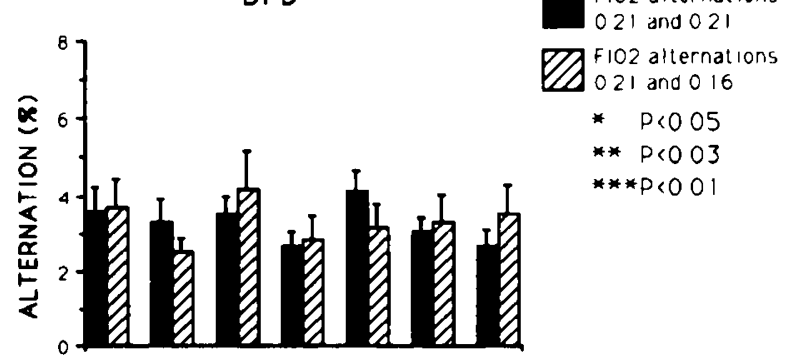

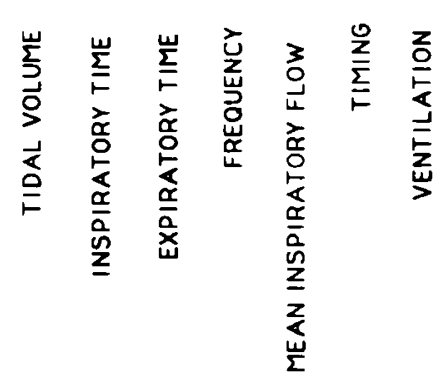

Fig. 3. The mean percentage breath-by-breath alternation for preterm control infants ( $n=31$ runs from 12 infants) and infants with BPD ( $n=$ 21 runs from eight infants). Mean responses \pm SEM are shown during control runs (solid bars) and test runs (hatched bars) for $V_{T}, T_{1}, T_{E}$, breath frequency, mean inspiratory flow, timing, and ventilation. Asterisks show significant differences between control and test runs: ${ }^{*}, p<0.05,{ }^{* *}, p<$ $0.03,{ }^{* * *}, p<0.01$ by Mann-Whitney $\mathrm{U}$ test. 
ognized by chemoreceptors in infants with BPD and preterm infants, yet the ventilatory response may be different because of impaired pulmonary mechanics. However, because the magnitude of the mean breath-by-breath response, even in preterm infants, is only approximately $10 \%$, and because the alternation does not take $\mathrm{V}_{\mathrm{T}}$ or respiratory timing outside their normal resting values, it seems unlikely that impaired pulmonary mechanics can account for the lack of a response in infants with BPD. Because pulmonary mechanical function was not measured in the infants with BPD, we do not know the peak inspiratory flow rates achieved to maintain adequate ventilation. If peak inspiratory flow was greater than $2.5 \mathrm{~L} / \mathrm{min}$ in the infants with BPD, then room air would also be inspired with the hypoxic gas mixture and the size of the stimulus would be subsequently reduced.

Sekar and Duke (26) reported that infants with BPD had lower oxygen saturations and a higher incidence of central apnea at the time of discharge than did healthy preterm infants, although the incidence of obstructive apnea or episodes of periodic breathing did not differ. Subsequent oxygen administration to increase saturation decreased the occurrence of central apnea and periodic breathing in infants with BPD. This evidence suggests that poor respiratory drive is responsible for the origin of apnea and periodic breathing. Our finding that respiratory chemoreflexes are reduced in such infants supports this idea, although it does not allow us to discriminate between two possibilities: I) that chemoreceptor input to the respiratory controller is reduced and 2) that the sensitivity of the respiratory controller to an adequate stimulus is reduced. Either way, the finding that infants with BPD have reduced chemoreceptor gain may have important consequences to those infants with BPD who die of SIDS.

Compromised infants with BPD, and to a lesser extent preterm infants, do in fact recover in the subsequent years. Mallory et al. (27) reported an improvement in forced vital capacity to normal levels by $36 \mathrm{mo}$ in infants with moderate BPD, with little improvement seen in lower airway obstruction and airway hyperreactivity. Other longitudinal studies reported normal total lung capacity and functional residual capacity in infants aged 7 and $10 \mathrm{y}$, with elevated mean residual volume at both ages $(28)$. An improvement was also seen in the forced expiratory volume during $1 \mathrm{~s}$ from y 7 to 10 . There is a need to perform longitudinal studies of the alternate breath test in infants who previously had BPD to determine whether the recovery seen in lung function measurements is reflected in improvements in respiratory chemoreflex sensitivity.

Acknowledgments. The authors thank Dr. Andrew Robbins and Dr. John Wyatt for their help in establishing the study at University College Hospital.

\section{REFERENCES}

1. Werthammer J, Brown ER. Neff RK. Taeusch HW 1982 Sudden infant death syndrome in infants with bronchopulmonary dysplasia. Pediatrics 69:301304

2. Teague WG, Pian MS. Heldt GP. Tooley WH 1988 An acute reduction in the fraction of inspired oxygen increases airway constriction in infants with chronic lung disease. Am Rev Respir Dis 137:861-865

3. Bryan MH, Hardie MJ, Reilly BJ, Swyer BR 1973 Pulmonary function studies during the first year of life in infants recovering from the respiratory distress syndrome. Pediatrics 52:169-178

4. Naeye RL 1980 Sudden infant death. Sci Am 242:56-62

5. Fewell JE. Kondo CS. Ddascalu V. Filyk SC 1989 Influence of carotiddenervation on the arousal and cardiopulmonary responses to alveolar hypercapnia in lambs. J Dev Physiol 12:193-199

6. Fewell JE, Kondo CS, Ddascalu V. Filyk SC 1989 Influence of carotid denervation on the arousal and cardiopulmonary response to rapidly developing hypoxemia in lambs. Pediatr Res 25:473-477

7. Haddad GG. Leistner HL, Epstein RA, Epstein MAF, Grodin WK. Mellins $\mathrm{RB} 1980 \mathrm{CO}_{2}$-induced changes in ventilation and ventilatory pattern in normal sleeping infants. J Appl Physiol 48:684-688

8. Cohen G. Henderson-Smart DJ 1990 A modified rebreathing method to study the ventilatory response of the newborn to $\mathrm{CO}_{2}$. J Dev Physiol 14:295-301

9. McCulloch K, Brouillette RT. Guzzetta AJ, Hunt CE 1982 Arousal responses in near-miss sudden infant death syndrome and in normal infants. J Pediatr 101:911-917

10. van der Hal AL. Rodriguez AM, Sargent CW. Platzker ACG, Keens TG 1985 Hypoxic and hypercapneic arousal responses and prediction of subsequent apnea in apnea of infancy. Pediatrics 75:848-854

11. Garg M, Kurzner SI, Bautista DB. Keens TG 1988 Hypoxic arousal responses in infants with bronchopulmonary dysplasia. Pediatrics 82:59-63

12. Hanson MA. Kumar P. Williams BA 1989 The effect of chronic hypoxia upon the development of respiratory chemoreflexes in the newborn kitten. J Physiol (Lond) 411:563-574

13. Williams BA, Hanson MA 1990 Role of the carotid chemoreceptors in the respiratory response of newborn lambs to alternate pairs of breaths of air and a hypoxic gas. J Dev Physiol 13:157-164

14. Williams BA, Smyth J, Boon AW, Hanson MA, Kumar P. Blanco CE 1991 Development of respiratory chemoreflexes in response to alternations of Development of respiratory chemoreflexes in response to alternations of
fractional inspired oxygen in the newborn infant. J Physiol (Lond) 442:8190

15. Blanco CE. Dawes GS. Hanson MA, McCooke HB 1984 The response to hypoxia of arterial chemoreceptors in fetal sheep and newborn lambs. J Physiol (Lond) 351:25-37

16. Hanson MA. Eden GJ, Nijhuis JG, Moore PJ 1989 Peripheral chemoreceptors and other $\mathrm{O}_{2}$ sensors in the fetus and newborn. In: Lahiri $S(e d)$ Chemoreceptors and Reflexes in Breathing: Systemic Cellular and Molecular Aspects. Oxford University Press, Oxford, pp 113-120

17. Prechtl HFR 1974 The behavioural states of the newborn infant (a review) Brain Res 76:185-212

18. Sackner MA, Watson H. Belsito AS, Feinerman D, Suarez M. Gonzalez G. Bizousky F. Krieger B 1989 Calibration of respiratory inductive plethysmograph during natural breathing. J Appl Physiol 66:410-420

19. Hanson MA, Kumar P. Williams BA 1987 Developmental changes in the reflex respiratory response to alternations of $F_{i, 02}$ in the newborn kitten. $J$ Physiol (Lond) 394:69P(abstr)

20. Calder NA, Williams BA, Kumar P, Hanson MA 1994 The respiratory response of healthy term infants to breath-by-breath alternations in inspired oxygen at two postnatal ages. Pediatr Res $35: 321-324$

21. Margraf LR. Tomashefski JF, Bruce MC, Dahms BB 1991 Morphometric analysis of the lung in bronchopulmonary dysplasia. Am Rev Respir Dis 143:391-400

22. Gorenflo M, Vogel M, Obalden M 1991 Pulmonary vascular changes in bronchopulmonary dysplasia: a clinicopathologic correlation in short- and long-term survivors. Pediatr Pathol 11:851-866

23. Kumar P. Nye PCG 1985 Comparison of responses of cat carotid body chemoreceptors to oscillations of $\mathrm{PCO}_{2}, \mathrm{PO}_{2}$ and asphyxia. J Physiol (Lond) 369:146P(abstr)

24. Kumar P. Nye PCG. Torrance RW 1988 Do oxygen tension variations contribute to the respiratory oscillations of chemoreceptor discharge in the cat? J Physiol (Lond) 395:531-552

25. Uyboco JS, Kwiatkowski K, Cates DB, Kavanagh L, Rigatto H 1989 Hypoxic airway constriction in infants of very low birth weight recovering from moderate to severe bronchopulmonary dysplasia. J Pediatr 115:456-459

26. Sekar KC. Duke JC 1991 Sleep apnea and hypoxemia in recently weaned premature infants with and without bronchopulmonary dysplasia. Pediatr Pulmonol 10:112-116

27. Mallory GB, Chaney H, Mutich RL, Motoyama EK 1991 Longitudinal changes in lung function during the first three years of premature infants with moderate to severe bronchopulmonary dysplasia. Pediatr Pulmonol 11:8-14

28. Blayney M, Kerem E, Whyte H, O'Brodovich H 1991 Bronchopulmonary dysplasia: improvement in lung function between 7 and 10 years of age. J Pediatr 118:201-206 